\title{
Qualidade nutricional e esverdeamento pós-colheita de tubérculos de cultivares de batata
}

\author{
Regina Marta Evangelista(1), Israel Nardin(1), Adalton Mazetti Fernandes ${ }^{(1)}$ e Rogério Peres Soratto(1) \\ (1)Universidade Estadual Paulista, Faculdade de Ciências Agronômicas, Campus de Botucatu, Caixa Postal 237, CEP 18603-970 Botucatu, SP. \\ E-mail: evangelista@fca.unesp.br, raelnardin@hotmail.com, adalton@fca.unesp.br, soratto@fca.unesp.br
}

\begin{abstract}
Resumo - O objetivo deste trabalho foi avaliar as características físico-químicas, a qualidade nutricional e a suscetibilidade ao esverdeamento pós-colheita de tubérculos de cultivares de batata. Utilizou-se o delineamento experimental de blocos ao acaso, com cinco repetições. Os tratamentos consistiram de 11 cultivares (Ágata, Ambra, Annabelle, Asterix, Atlantic, Cupido, Daisy, Fontane, Innovator, Markies e Voyager). As cultivares Ágata, Ambra, Annabelle, Cupido e Voyager apresentam tubérculos com polpa de menor firmeza (6,82 a 8,25 N) e baixos teores de matéria seca (14,46 a 17,57\%), carboidratos (10,97 a 12,51\%) e amido (10,21 a 12,26\%), adequados para o mercado fresco, a preparação de massas e o uso culinário. Já as cultivares Atlantic, Fontane e Innovator apresentam polpa firme $(9,14$ a 9,55 N) e elevados teores de matéria seca (19,68 a 21,63\%), carboidratos (14,49 a 15,90\%) e amido (14,29 a 15,74\%), adequados para fritura. As cultivares Asterix e Markies apresentam teores intermediários dessas características e são indicadas para o preparo de massas e fritura. As cultivares Innovator e Markies apresentam melhor qualidade nutricional, com elevados teores de minerais ( $\mathrm{P}, \mathrm{K}, \mathrm{Mg}, \mathrm{Cu}$ e $\mathrm{Mn}$ ) e de proteína, enquanto as cultivares Ágata e Ambra apresentam menor qualidade nutricional e proteica. A cultivar Voyager apresenta maior esverdeamento pós-colheita que as cultivares Annabelle, Fontane, Markies, Ambra e Atlantic.
\end{abstract}

Termos para indexação: Solanum tuberosum, açúcares redutores, aspecto visual, cor da película, matéria seca.

\section{Nutritional quality and postharvest greening of tubers from potato cultivars}

\begin{abstract}
The objective of this work was to evaluate the physicochemical characteristcs, nutritional quality, and susceptibility to postharvest greening of tubers from potato cultivars. A randomized complete block design with five replicates was used. Treatments consisted of 11 potato cultivars (Ágata, Ambra, Annabelle, Asterix, Atlantic, Cupido, Daisy, Fontane, Innovator, Markies and Voyager). Cultivars Ágata, Ambra, Annabelle, Cupido, and Voyager have the lowest pulp firmness $(6.82$ to $8.25 \mathrm{~N})$ and low dry matter (14.46 to $17.57 \%)$, carbohydrate (10.97 to $12.51 \%$ ), and starch content (10.21 to $12.26 \%$ ), appropriate for the fresh market, preparing pasta, and culinary use. Cultivars Atlantic, Fontane, and Innovator have firm pulp $(9.14$ to $9.55 \mathrm{~N})$ and high dry matter (19.68 to $21.63 \%$ ), carbohydrate (14.49 to $15.90 \%$ ), and starch content (14.29 to $15.74 \%$ ), suitable for frying. Cultivars Asterix and Markies show intermediate levels of these characteristics and are suitable for making pasta and frying. Cultivars Innovator and Markies have better nutritional quality with high content of minerals (P, K, $\mathrm{Mg}, \mathrm{Cu}$, and $\mathrm{Mn}$ ) and protein, while cultivars Ágata and Ambra have lower nutritional quality and protein content. Cultivar Voyager has higher postharvest greening than Annabelle, Fontane, Markies, Ambra and Atlantic.
\end{abstract}

Index terms: Solanum tuberosum, reducing sugars, visual aspect, skin color, dry matter.

\section{Introdução}

A batata (Solanum tuberosum L.) é uma das mais importantes fontes de alimento para a população humana, em virtude da elevada produtividade e qualidade nutricional de seus tubérculos. No mercado, os tubérculos são escolhidos por suas características visuais, como forma, cor, brilho da pele, ausência de defeitos, e pelo preço de comercialização (Feltran et al., 2004b). Entretanto, cada vez mais, os consumidores têm priorizado as qualidades nutricionais e culinárias dos tubérculos e buscado informações sobre a melhor forma de preparo e utilização da batata (Feltran et al., 2004b; Silva et al., 2007).

A aptidão culinária dos tubérculos depende de sua composição físico-química, que é influenciada pela adubação e pela cultivar utilizada (Quadros et al., 2009; Fernandes et al., 2010a). Outro fator que interfere na comercialização da batata é o desenvolvimento de cor verde nos tubérculos, que, além de comprometer a aceitação pelo mercado consumidor, resulta em prejuízos a toda a cadeia produtiva da batata

Pesq. agropec. bras., Brasília, v.46, n.8, p.953-960, ago. 2011 
(Feltran et al., 2004a). A coloração verde envolve, também, um componente genético, que resulta em diferenças nas reações dos genótipos e das cultivares, quando expostos às mesmas condições indutoras (Grunenfelder et al., 2006). Portanto, a identificação e a utilização de cultivares de batata com tubérculos resistentes ao esverdeamento é uma das formas de minimizar as perdas durante a comercialização.

No Brasil, o consumo de batata industrializada aumentou nos últimos anos. No entanto, a produção nacional está concentrada em um número restrito de cultivares. As cultivares Ágata, Asterix, Atlantic, Markies e Mondial estão entre as mais plantadas no Brasil (Fernandes et al., 2010b) e representam a maior parcela de toda a área plantada com batata no país. Contudo, apenas a cultivar Atlantic tem sido utilizada em grande escala na indústria de processamento. Embora o uso de novas cultivares de batata nas regiões produtoras do Brasil esteja em expansão (Feltran et al., 2004a), ainda faltam informações sobre a melhor forma de utilizá-las e sobre a suscetibilidade de seus tubérculos ao esverdeamento pós-colheita, o que pode comprometer sua comercialização.

O objetivo deste trabalho foi avaliar as características físico-químicas, a qualidade nutricional e a suscetibilidade ao esverdeamento de tubérculos de 11 cultivares de batata.

\section{Material e Métodos}

Tubérculos de 11 cultivares de batata produzidos na safra de inverno de 2008 (junho a setembro), em área produtora de batata, no Município de Cristalina, GO $\left(16^{\circ} 10^{\prime} \mathrm{S} ; 47^{\circ} 28^{\prime} \mathrm{W}\right)$, foram utilizados para as análises. Durante a condução da cultura no campo, foram realizados todos os tratos culturais de acordo com as recomendações para a cultura e os critérios adotados pelo produtor. Os tubérculos foram colhidos em 2/9/2008, no estádio de maturação comercial para consumo, e transportados para o laboratório onde foram realizadas as análises físico-químicas, nutricionais e de suscetibilidade ao esverdeamento.

Utilizou-se o delineamento experimental de blocos ao acaso, com 5 repetições e 11 tratamentos, representados pelas cultivares de batata Ágata, Ambra, Annabelle, Asterix, Atlantic, Cupido, Daisy, Fontane, Innovator, Markies e Voyager. Cada repetição foi composta por uma amostra de três tubérculos, com peso médio de 120 a $200 \mathrm{~g}$.

A firmeza da polpa foi determinada em cada um dos três tubérculos (com casca), de cada unidade experimental, tendo-se utilizado texturômetro Stevens LFRA Texture Analyser, (Labequip, Ltd., Markham, Ontário, Canadá) com profundidade de penetração de $20 \mathrm{~mm}$, velocidade de $2,0 \mathrm{~mm} \mathrm{~s}^{-1}$ e ponteiro TA 9/1000. $\mathrm{Na}$ quantificação dos sólidos solúveis (SS), algumas fatias da polpa foram maceradas, e duas gotas do suco foram colocadas no prisma do refratômetro eletrônico modelo PR-32 (Atago U.S.A, Inc., Bellevue, WA, EUA). Os teores de SS foram determinados conforme Horwitz \& Latimer Junior (2005), e os resultados expressos em ${ }^{\circ}$ Brix. Para determinação da acidez titulável, $10 \mathrm{~g}$ de polpa triturada foram diluídos em $100 \mathrm{~mL}$ de água destilada, e a mistura foi filtrada e titulada com solução de hidróxido de sódio a $0,1 \mathrm{~N}$, tendo-se utilizado como indicador a fenolftaleína (Zenebom \& Pascuet, 2005). A determinação do $\mathrm{pH}$ foi realizada com $10 \mathrm{~g}$ de polpa, triturados em $100 \mathrm{~mL}$ de água destilada, em que foi feita a leitura direta do $\mathrm{pH}$, com medidor de $\mathrm{pH}$ digital, modelo DM-2, (Digimed, São Paulo, SP) (Zenebom \& Pascuet, 2005). O teor de matéria seca foi determinado por secagem da polpa dos tubérculos em estufa a $105^{\circ} \mathrm{C}$, com circulação de ar até peso constante (Zenebom \& Pascuet, 2005). Os teores de amido, açúcares redutores e totais foram determinados na matéria seca, segundo metodologia de Somogyi, adaptada por Nelson (1944), e as leituras foram realizadas em espectrofotômetro a $535 \mathrm{~nm}$. Os dados de açúcares e amido foram convertidos para teores na matéria fresca, e os teores de carboidratos foram obtidos pela soma dos teores de amido e açúcares totais.

O teor de proteína nos tubérculos foi determinado na matéria seca, com o método de Kjeldahl (método 920.87 da Association of Analytical Chemists - AOAC) (Horwitz \& Latimer Junior, 2005) e com o fator de 6,25 para conversão em proteína bruta. Em seguida, os dados foram convertidos para teores de proteína na matéria fresca. As cinzas foram determinadas pela calcinação em mufla a $550^{\circ} \mathrm{C}$ (método 942.05 da AOAC) (Horwitz \& Latimer Junior, 2005). A determinação de fibra alimentar total nos tubérculos seguiu a AOAC (Horwitz \& Latimer Junior, 2005). Os teores de minerais foram determinados nas amostras secas (Malavolta et al., 1997), e os valores obtidos convertidos para mg por $100 \mathrm{~g}$ de matéria fresca. 
Para a avaliação de esverdeamento pós-colheita, utilizou-se o mesmo delineamento da avaliação das características físico-químicas. Porém, foram utilizados dez tubérculos por repetição, dos quais cinco foram mantidos embrulhados em papel alumínio para isolar o efeito da luz (testemunha). Os tubérculos foram armazenados sobre uma bancada por 25 dias, tendo permanecido expostos à luz natural (exceto as testemunhas). A intensidade de luz durante o experimento foi medida com luxímetro às $8,14 \mathrm{e}$ 16h30, em cinco pontos aleatórios sobre a mesa onde foram dispostos os tubérculos. A intensidade de luz no laboratório, durante a condução do experimento, foi de $320 \pm 50 \mathrm{Lux}$, e a temperatura média de $23,4 \pm 4,6^{\circ} \mathrm{C}$, com $72 \pm 5 \%$ de umidade relativa.

As avaliações da intensidade de esverdeamento dos tubérculos foram realizadas após $5,10,15,20 \mathrm{e}$ 25 dias de exposição à luz. A cor foi medida em cada tubérculo com colorímetro modelo CR-400 (Konica Minolta Sensing Americas, Inc., Ramsey, NJ, EUA), com determinação dos parâmetros $\mathrm{L}^{*}, \mathrm{a}^{*} \mathrm{e} \mathrm{b}^{*}$. Com os valores de $L^{*}, a^{*} e b^{*}$, foram calculadas as diferenças de cor dos tubérculos expostos à luz, em comparação à cor da testemunha (envolvida em papel alumínio), com uso da fórmula:

$$
\Delta \mathrm{E}=\left[\left(\Delta \mathrm{L}^{*}\right)^{2}+\left(\Delta \mathrm{a}^{*}\right)^{2}+\left(\Delta \mathrm{b}^{*}\right)^{2}\right]^{0,5},
$$

(Konica Minolta, 1998), em que: $\Delta \mathrm{E}$ é o valor para diferença de cor; $\Delta \mathrm{L}^{*}$ é a diferença entre a leitura $\mathrm{L}^{*}$ da testemunha e a leitura $L^{*}$ dos tubérculos expostos à luz; $\Delta \mathrm{a}^{*}$ é a diferença entre a leitura $\mathrm{a}^{*}$ da testemunha e a leitura $\mathrm{a}^{*}$ dos tubérculos expostos à luz; $\Delta \mathrm{b}^{*}$ é a diferença entre a leitura $b^{*}$ da testemunha e a leitura $b^{*}$ dos tubérculos expostos à luz. Os valores de diferença de cor foram interpretados de acordo com a escala de variação da diferença total de cores (Konica Minolta, 1998), em que: $\Delta \mathrm{E}<0,2$, diferença de cor imperceptível; $\Delta \mathrm{E}$ de 0,2 a 0,5 , diferença de cor muito pequena; $\Delta \mathrm{E}$ de 0,5 a 1,5 , diferença de cor pequena; $\Delta \mathrm{E}$ de 1,5 a 3,0 , diferença de cor distinguível; $\Delta \mathrm{E}$ de 3,0 a 6,0 , diferença de cor facilmente distinguível; $\Delta \mathrm{E}$ de 6,0 a 12,0 , diferença de cor grande; $\Delta \mathrm{E}>12,0$, diferença de cor muito grande.

Os resultados foram submetidos à análise de variância, e as médias foram comparadas pelo teste de Tukey, a 5\% de probabilidade.

\section{Resultados e Discussão}

As cultivares Markies, Innovator, Cupido, Daisy, Fontane e Asterix apresentaram polpa mais firme, enquanto a cultivar Ágata apresentou polpa com menor firmeza (Tabela 1). Feltran et al. (2004b) e Fernandes et al. (2010a) também observaram diferenças significativas entre cultivares de batata, quanto aos valores de firmeza da polpa, e relataram que a cultivar Ágata foi uma das que apresentou polpa com menor firmeza. Segundo Pereira et al. (2005), cultivares que apresentam polpa mais firme, como Markies, Innovator, Cupido, Daisy, Fontane e Asterix, são mais indicadas para o preparo de massas.

Os valores de $\mathrm{SS}\left({ }^{\circ} \mathrm{Brix}\right)$ foram maiores nas cultivares Innovator e Markies, e as cultivares Ágata, Ambra, Asterix, Cupido e Voyager apresentaram os menores valores dessa variável (Tabela 1). Nas demais cultivares, os teores de SS apresentaram valores intermediários. Como os SS são constituídos, principalmente, por açúcares (sacarose), os maiores teores de SS nos tubérculos das cultivares Innovator e Markies são indicativos de maiores conteúdos de sacarose, o que não indica baixa qualidade dos tubérculos (Pereira, 1987). Feltran et al. (2004b) obtiveram valores de SS acima de 5,0, para a maioria das cultivares avaliadas. Pinelli et al. (2005) observaram valores de SS de 3,9 a 4,8 , na cultivar Ágata.

Houve diferença significativa entre as cultivares avaliadas quanto aos valores de acidez titulável. Os maiores valores foram observados nas cultivares Ágata, Cupido e Voyager, e o menor na cultivar Daisy (Tabela 1). Nas demais cultivares, os valores de acidez titulável foram semelhantes, o que é evidência da pequena variação entre cultivares quanto à quantidade de ácidos orgânicos presentes na polpa. Feltran et al. (2004b) e Fernandes et al. (2010a) também obtiveram pequena ou nenhuma diferença significativa entre os valores de acidez titulável, para a maioria das cultivares testadas.

Nas cultivares Daisy, Markies, Atlantic e Fontane, foram obtidos os maiores valores de $\mathrm{pH}$ da polpa, enquanto a cultivar Cupido apresentou o menor valor para essa variável (Tabela 1). No geral, os valores de $\mathrm{pH}$ da polpa de todas as cultivares avaliadas estavam acima de 6,0, o que indica que os tubérculos se encontravam em bom estado de maturação e conservação, pois os valores de $\mathrm{pH}$ ótimos para a ação das enzimas que 
degradam o amido são mais baixos, ou seja, entre $\mathrm{pH}$ 5,5 e 4,7 (Feltran et al., 2004b).

As cultivares Atlantic e Innovator apresentaram teores de matéria seca e carboidratos superiores aos das demais cultivares, com teores de matéria seca acima de $21 \%$ e de carboidratos maiores que $15,7 \%$ (Tabela 1 ). Os menores valores de matéria seca e carboidratos foram obtidos nas cultivares Ágata e Ambra. Tubérculos com maiores teores de carboidratos e matéria seca e com menores teores de água são mais adequados à fritura e ao preparo de purês (Pereira et al., 2005), pois favorecem o rendimento da fritura e a produção de batata chips, o que proporciona menor absorção de óleo durante a fritura e garante maior crocância ao produto final (Zorzella et al., 2003). De acordo com Oliveira et al. (2006), o teor de matéria seca dos tubérculos destinados ao processamento na forma de chips deve ser de pelo menos $20 \%$, para a obtenção de produto de alta qualidade; entretanto, teores de matéria seca superiores a $24 \%$ são indesejados porque produzem fatias quebradiças e causam desgaste excessivo das máquinas fatiadoras. Assim, segundo esses autores, as cultivares mais aptas ao processamento na forma de chips são Innovator, Atlantic e Fontane. Cultivares com menor teor de matéria seca, em seus tubérculos, como Ágata e Ambra, são mais firmes no cozimento e são indicadas para a preparação de pratos assados, nos quais a manutenção de sua forma é essencial (Pereira, 1987).

Os teores de amido nas cultivares Innovator e Atlantic foram superiores aos das demais cultivares, com 15,74 e 15,35\% da matéria fresca dos tubérculos, respectivamente (Tabela 1). Embora a percentagem de amido nos tubérculos tenha sido maior nessas cultivares, não houve diferença significativa entre as cultivares Fontane e Markies. Quadros et al. (2009) observaram teores de amido nos tubérculos das cultivares Innovator e Atlantic acima de $16 \%$ da matéria fresca, isto é, superiores aos obtidos no presente trabalho, para as mesmas cultivares. Braun et al. (2010), ao avaliar as cultivares Ágata, Asterix, Atlantic e Monalisa, observaram teores de amido de 10,97, 13,32, 11,31 e 13,30\%, respectivamente, valores semelhantes aos obtidos para as cultivares Ágata e Asterix. Essas diferenças observadas entre autores, provavelmente, são decorrentes das práticas culturais adotadas na condução da cultura, como adubação potássica, que altera o teor de amido nos tubérculos (Quadros et al., 2009), ou diferenças na época de plantio.

Houve relação entre os teores de carboidratos, matéria seca e amido, pois as cultivares Innovator e Atlantic apresentaram elevados valores dessas variáveis (Tabela 1). Isso ocorreu em virtude de o amido ser o carboidrato presente em maior quantidade nos tubérculos e representar de 60 a $80 \%$ da sua matéria seca (Freitas et al., 2006). Além disso, o amido apresenta influência direta na textura dos produtos processados.

Quanto ao teor de açúcares redutores, os maiores teores foram obtidos nos tubérculos da cultivar Ágata $(0,47 \%)$, e os menores na cultivar Daisy $(0,08 \%)$ (Tabela 1). Nas demais cultivares, os teores de açúcares redutores apresentaram valores intermediários e variaram de $0,31 \%$ (Annabelle) a $0,11 \%$ (Innovator) da matéria fresca. Stark et al. (2003) relataram que as batatas devem apresentar teores de açúcares redutores,

Tabela 1. Composição físico-química de tubérculos de cultivares de batata, produzidos na safra de inverno de $2008^{(1)}$.

\begin{tabular}{|c|c|c|c|c|c|c|c|c|c|c|c|}
\hline Cultivar & $\begin{array}{l}\text { Firmeza } \\
(\mathrm{N})\end{array}$ & $\begin{array}{c}\text { Sólidos solúveis } \\
\left({ }^{\circ} \text { Brix }\right)\end{array}$ & $\begin{array}{l}\text { Acidez titulável }{ }^{(2)} \\
\text { (\% ácido cítrico) }\end{array}$ & pH polpa & Matéria seca & Carboidratos & $\begin{array}{l}\text { Amido } \\
\text { (9) }\end{array}$ & $\begin{array}{l}\text { Açúcares redutores } \\
\text { da matéria fresca) }\end{array}$ & Cinzas & Proteínas & Fibras \\
\hline Ágata & $6,82 \mathrm{~d}$ & $4,30 \mathrm{e}$ & $0,286 \mathrm{a}$ & $6,30 \mathrm{bcd}$ & $14,46 \mathrm{~g}$ & $10,97 \mathrm{~d}$ & $10,21 \mathrm{f}$ & $0,466 \mathrm{a}$ & $0,86 \mathrm{~d}$ & $1,42 \mathrm{~d}$ & $0,34 \mathrm{a}$ \\
\hline Ambra & $7,35 \mathrm{~cd}$ & $4,14 \mathrm{e}$ & $0,205 \mathrm{bc}$ & $6,42 \mathrm{bcd}$ & $16,15 f$ & $11,27 d$ & $11,06 \mathrm{ef}$ & $0,148 \mathrm{cde}$ & $0,84 \mathrm{~d}$ & $1,60 \mathrm{~cd}$ & $0,35 \mathrm{a}$ \\
\hline Annabelle & $8,25 b c$ & $4,70 \mathrm{~cd}$ & $0,228 b c$ & $6,42 \mathrm{bcd}$ & $17,08 \mathrm{ef}$ & $12,07 \mathrm{~cd}$ & $11,62 \mathrm{def}$ & $0,314 b$ & $0,87 \mathrm{~d}$ & $1,69 \mathrm{bcd}$ & $0,34 \mathrm{a}$ \\
\hline Asterix & $8,81 \mathrm{ab}$ & $4,28 \mathrm{e}$ & $0,222 b c$ & $6,21 \mathrm{~cd}$ & $18,46 \mathrm{~cd}$ & $13,37 \mathrm{bc}$ & $12,93 \mathrm{bcd}$ & $0,274 b$ & $0,95 \mathrm{~cd}$ & $1,69 \mathrm{bcd}$ & $0,45 \mathrm{a}$ \\
\hline Atlantic & $9,43 \mathrm{a}$ & $4,96 \mathrm{cb}$ & $0,227 b c$ & $6,52 \mathrm{ab}$ & $21,63 a$ & $15,82 \mathrm{a}$ & $15,35 \mathrm{a}$ & $0,260 \mathrm{bc}$ & $1,12 \mathrm{abc}$ & $1,92 \mathrm{abc}$ & $0,37 \mathrm{a}$ \\
\hline Cupido & $7,79 \mathrm{~cd}$ & $4,40 \mathrm{de}$ & $0,292 \mathrm{a}$ & $6,17 \mathrm{~d}$ & $16,81 \mathrm{ef}$ & $12,35 \mathrm{~cd}$ & 12,09 cde & $0,204 \mathrm{bcd}$ & $0,97 \mathrm{~cd}$ & $1,62 \mathrm{~cd}$ & $0,41 \mathrm{a}$ \\
\hline Daisy & $9,10 \mathrm{ab}$ & $4,92 \mathrm{cb}$ & $0,190 \mathrm{c}$ & $6,72 \mathrm{a}$ & $19,14 \mathrm{bc}$ & $13,57 b c$ & $13,49 b c$ & $0,084 \mathrm{e}$ & $1,01 \mathrm{bcd}$ & $1,82 \mathrm{abc}$ & $0,37 \mathrm{a}$ \\
\hline Fontane & $9,14 \mathrm{ab}$ & $4,84 \mathrm{cb}$ & $0,222 b c$ & $6,48 \mathrm{abc}$ & $20,09 b$ & $14,49 \mathrm{ab}$ & $14,29 a b$ & $0,144 \mathrm{cde}$ & $1,25 \mathrm{a}$ & $2,06 \mathrm{a}$ & $0,41 \mathrm{a}$ \\
\hline Innovator & $9,43 \mathrm{a}$ & $5,36 \mathrm{a}$ & $0,222 b c$ & $6,41 \mathrm{bcd}$ & $21,35 \mathrm{a}$ & $15,90 \mathrm{a}$ & $15,74 \mathrm{a}$ & 0,114 de & $1,13 \mathrm{abc}$ & $2,03 a b$ & $0,34 \mathrm{a}$ \\
\hline Markies & $9,55 \mathrm{a}$ & $5,06 \mathrm{ab}$ & $0,218 \mathrm{bc}$ & $6,49 \mathrm{ab}$ & $19,68 \mathrm{bc}$ & $14,58 \mathrm{ab}$ & $14,36 \mathrm{ab}$ & $0,148 \mathrm{cde}$ & $1,21 \mathrm{ab}$ & $2,03 \mathrm{ab}$ & $0,45 \mathrm{a}$ \\
\hline Voyager & $7,78 \mathrm{~cd}$ & $4,38 \mathrm{de}$ & $0,251 \mathrm{ab}$ & $6,40 \mathrm{bcd}$ & $17,57 \mathrm{de}$ & $12,51 \mathrm{~cd}$ & $12,26 \mathrm{cde}$ & $0,152 \mathrm{cde}$ & $0,94 \mathrm{~cd}$ & $1,78 \mathrm{abcd}$ & $0,32 \mathrm{a}$ \\
\hline$\overline{\mathrm{CV}(\%)}$ & 7,8 & 3,3 & 10,4 & 2,0 & 4,7 & 5,4 & 5,9 & 26,2 & 14,3 & 9,3 & 23,5 \\
\hline
\end{tabular}

${ }^{(1)}$ Médias seguidas de letras iguais, nas colunas, não diferem entre si pelo teste Tukey, a 5\% de probabilidade. ${ }^{(2)}$ Percentagem de ácido cítrico por 100 g de matéria fresca. 
geralmente abaixo de $0,035 \%$ da massa fresca, para processamento na forma de chips, e de $0,12 \%$, quando processadas na forma de palitos. Portanto, segundo esses autores, nas condições de cultivo de inverno, apenas a cultivar Daisy apresentou teores de açúcares redutores adequados para o processamento na forma de palitos, e nenhuma das cultivares é adequada para o processamento na forma de chips. Contudo, embora os teores de açúcares redutores estejam, normalmente, correlacionados aos valores de cor dos chips (Feltran et al., 2004b), Fernandes et al. (2010a) verificaram que cultivares com teores de açúcares redutores considerados inadequados para a fritura na forma de palitos e chips apresentaram tanto palitos quanto chips de cor aceitável, além de palitos com cor de alta qualidade. Esses autores atribuíram esses resultados à concentração de aminoácidos e polifenóis totais que também têm mostrado certa influência sobre a intensidade de coloração das batatas fritas (Zorzella et al., 2003; Freitas et al., 2006). Assim, a avaliação apenas do teor de açúcares redutores não é suficiente para distinguir cultivares quanto à aptidão para $o$ processamento industrial. Também é fundamental avaliar a cor da fritura para uma conclusão mais apurada, uma vez que a cor é considerada um dos parâmetros mais importantes na definição da qualidade das batatas fritas (Pedreschi et al., 2007).

Foram observadas diferenças entre as cultivares quanto ao teor de proteínas nos tubérculos (Tabela 1). As cultivares Atlantic, Daisy, Fontane, Innovator, Markies e Voyager apresentaram teores semelhantes e relativamente superiores aos obtidos nas demais cultivares. As cultivares Ágata, Ambra eCupido, embora tenham apresentado teor de proteína semelhante ao de outras cultivares, foram as que obtiveram os menores valores dessa variável. Esses resultados estão de acordo com os de Lachman et al. (2005), em que os teores de proteína nos tubérculos da batateira são afetados por diversos fatores, como cultivares, sistemas de adubação e sistemas de manejo da cultura. Portanto, apesar de geralmente não ser considerada como uma fonte rica em proteína, em virtude de seu baixo teor (Lachman et al., 2005), a batata apresenta proteína de alto valor nutritivo e, consequentemente, é uma importante fonte de alimento (Bártová \& Bárta, 2009).

Os maiores teores de cinzas foram obtidos nos tubérculos da cultivar Fontane, a qual não diferiu significativamente das cultivares Atlantic, Innovator e
Markies (Tabela 1). Já as cultivares Ágata, Ambra e Annabelle, apresentaram os menores teores de cinzas nos tubérculos. Fernandes et al. (2010a) também observaram que a cultivar Ágata apresentou os menores teores de cinzas, entre as cultivares testadas. Embora os teores de cinzas nos tubérculos de algumas cultivares tenham sido superiores aos obtidos por Quadros et al. (2009), a grande maioria das cultivares apresentou teores de cinzas semelhantes, que variaram de $0,87 \%$, na cultivar Asterix, a 0,93\%, na cultivar Atlantic.

Com relação ao teor de fibras, não houve diferença significativa entre as cultivares avaliadas (Tabela 1). Fernandes et al. (2010a) também não constataram diferenças entre cultivares quanto aos teores de fibra nos tubérculos. No presente trabalho, os teores de fibra não diferiram entre as cultivares, e os valores obtidos ficaram dentro do intervalo de 0,17 a 3,48\% da matéria fresca, relatado por Lister \& Munro (2000).

As cultivares Innovator e Markies apresentaram os maiores teores de $\mathrm{P}$ e $\mathrm{Mg}$, enquanto o menor teor de $\mathrm{Mg}$ foi obtido nos tubérculos da cultivar Ágata e os menores teores de $\mathrm{P}$ nos tubérculos das cultivares Ágata e Ambra (Tabela 2). Para as concentrações de $\mathrm{K}$, os maiores teores foram observados nos tubérculos das cultivares Atlantic, Fontane, Innovator e Markies, e os menores teores nos tubérculos da cultivar Ágata, ou seja, os teores desse nutriente variaram de 479 (Innovator) a 330 (Ágata) mg por 100 g. Os valores obtidos ficaram dentro da faixa de 352,50 a $549,91 \mathrm{mg}$ por $100 \mathrm{~g}$ de K, obtidos por Quadros et al. (2009).

Quanto ao $\mathrm{Ca}$, apenas a cultivar Innovator, que apresentou teor de $22 \mathrm{mg}$ por $100 \mathrm{~g}$ de matéria fresca de $\mathrm{Ca}$, diferiu das cultivares Markies (9 mg por $100 \mathrm{~g}$ ) e Ágata (9 mg por $100 \mathrm{~g}$ ). Nas demais cultivares, os teores de $\mathrm{Ca}$ foram semelhantes (Tabela 2). Os teores de Ca obtidos nos tubérculos da maioria das cultivares avaliadas foram inferiores aos valores de 18,15, 18,22 e 21,77 mg por $100 \mathrm{~g}$, obtidos por Misra \& Kulshrestha (2003), em três cultivares de batata. Somente a cultivar Innovator apresentou teor de $\mathrm{Cu}$ nos tubérculos superior ao das cultivares Ambra, Asterix e Fontane. Nas demais cultivares, não houve diferença significativa entre os teores desse elemento. Os teores de Fe e $\mathrm{Zn}$ não diferiram significativamente entre as cultivares testadas e foram, em média, 0,73 e $0,12 \mathrm{mg}$ por $100 \mathrm{~g}$ de matéria fresca de tubérculos, respectivamente. Misra \& Kulshrestha (2003), ao avaliar o efeito do armazenamento na qualidade nutricional de três 
cultivares de batata, verificaram teores médios de Fe, de 3,82 $\mathrm{mg}$ por $100 \mathrm{~g}$, superiores aos obtidos em todas as cultivares avaliadas. Entretanto, as cultivares e as condições nas quais os tubérculos foram produzidos diferiram das do presente trabalho. Os teores de $\mathrm{Mn}$ obtidos nos tubérculos das cultivares Atlantic, Cupido, Fontane e Voyager foram inferiores aos da cultivar Ágata.

Com relação ao esverdeamento pós-colheita, houve aumento na diferença de cor da película dos tubérculos $(\Delta \mathrm{E})$ com o avanço do período de exposição à luz (Tabela 3). Resultados semelhantes foram obtidos por outros autores (Brune \& Melo, 2001; Feltran et al., 2004a; Grunenfelder et al., 2006; Fernandes et al., 2011). Muraja-Fras et al. (1994) relataram que o esverdeamento dos tubérculos expostos à luz começa no primeiro dia de exposição à luz, quando os amiloplastos presentes na película dos tubérculos iluminados começam a transformar-se em cloroplastos. No entanto, são necessários alguns dias para que ocorram as primeiras alterações visíveis de coloração na película do tubérculo (Brune \& Melo, 2001).

Com cinco dias de armazenamento, a intensidade de esverdeamento não diferiu entre as cultivares, embora a diferença de cor em todas as cultivares já apresentasse valores acima de 4,0, tornando-se facilmente distinguível (Tabela 3). Aos dez dias de exposição à luz, as cultivares Voyager e Atlantic apresentaram maior diferença de cor que a cultivar Annabelle. Contudo, a intensidade de esverdeamento não diferiu

Tabela 2. Teores de nutrientes (mg por $100 \mathrm{~g}$ de matéria fresca) em tubérculos de cultivares de batata, produzidos na safra de inverno de $2008^{(1)}$.

\begin{tabular}{|c|c|c|c|c|c|c|c|c|}
\hline Cultivar & $\mathrm{P}$ & $\mathrm{K}$ & $\mathrm{Ca}$ & $\mathrm{Mg}$ & $\mathrm{Cu}$ & $\mathrm{Fe}$ & $\mathrm{Mn}$ & $\mathrm{Zn}$ \\
\hline Ágata & $43 e$ & $330 \mathrm{e}$ & $9 \mathrm{c}$ & $18 f$ & $0,37 \mathrm{ab}$ & $1,23 \mathrm{a}$ & $0,16 a$ & $0,12 \mathrm{a}$ \\
\hline Ambra & $43 e$ & $368 \mathrm{~cd}$ & $14 \mathrm{abc}$ & $23 \mathrm{de}$ & $0,22 \mathrm{~b}$ & $0,91 \mathrm{a}$ & $0,12 \mathrm{ab}$ & $0,09 \mathrm{a}$ \\
\hline Annabelle & $46 \mathrm{de}$ & 349de & $14 \mathrm{abc}$ & $22 \mathrm{ef}$ & $0,37 \mathrm{ab}$ & $0,72 \mathrm{a}$ & $0,11 \mathrm{ab}$ & $0,25 \mathrm{a}$ \\
\hline Asterix & $48 \mathrm{cde}$ & $387 \mathrm{~cd}$ & $16 a b c$ & $25 \mathrm{cde}$ & $0,24 b$ & $0,62 \mathrm{a}$ & $0,14 a b$ & $0,06 \mathrm{a}$ \\
\hline Atlantic & $54 b c$ & $454 \mathrm{ab}$ & $18 \mathrm{abc}$ & $27 \mathrm{~cd}$ & $0,35 \mathrm{ab}$ & $0,50 \mathrm{a}$ & $0,09 b$ & $0,12 \mathrm{a}$ \\
\hline Cupido & $50 \mathrm{cde}$ & $372 \mathrm{~cd}$ & $15 \mathrm{abc}$ & $23 \mathrm{de}$ & $0,42 \mathrm{ab}$ & $0,58 \mathrm{a}$ & $0,09 b$ & $0,10 \mathrm{a}$ \\
\hline Daisy & $54 \mathrm{bc}$ & $438 b$ & $14 \mathrm{abc}$ & $26 \mathrm{~cd}$ & $0,38 \mathrm{ab}$ & $0,49 a$ & $0,13 \mathrm{ab}$ & $0,12 \mathrm{a}$ \\
\hline Fontane & $56 \mathrm{bc}$ & $456 \mathrm{ab}$ & $19 \mathrm{ab}$ & $28 b c$ & $0,26 \mathrm{~b}$ & $0,58 \mathrm{a}$ & $0,08 \mathrm{~b}$ & $0,05 \mathrm{a}$ \\
\hline Innovator & $59 \mathrm{ab}$ & $479 a$ & $22 \mathrm{a}$ & $32 \mathrm{a}$ & $0,66 \mathrm{a}$ & $0,72 \mathrm{a}$ & $0,11 \mathrm{ab}$ & $0,25 \mathrm{a}$ \\
\hline Markies & $66 a$ & $458 \mathrm{ab}$ & $14 b c$ & $32 \mathrm{ab}$ & $0,34 \mathrm{ab}$ & $1,14 \mathrm{a}$ & $0,14 \mathrm{ab}$ & $0,07 \mathrm{a}$ \\
\hline Voyager & $52 \mathrm{bcd}$ & $410 \mathrm{c}$ & $16 \mathrm{abc}$ & $25 \mathrm{cde}$ & $0,29 \mathrm{ab}$ & $0,53 \mathrm{a}$ & $0,09 \mathrm{~b}$ & $0,06 \mathrm{a}$ \\
\hline CV (\%) & 6,8 & 3,1 & 26,2 & 7,3 & 49,2 & 63,0 & 24,6 & 77,8 \\
\hline
\end{tabular}

${ }^{(1)}$ Médias seguidas de letras iguais, nas colunas, não diferem entre si pelo teste Tukey, a 5\% de probabilidade.

Tabela 3. Diferença de cor $(\Delta \mathrm{E})$ em relação à testemunha, medida na casca de tubérculos de cultivares de batata, produzidos na safra de inverno de $2008^{(1)}$.

\begin{tabular}{|c|c|c|c|c|c|}
\hline \multirow[t]{2}{*}{ Cultivar } & \multicolumn{5}{|c|}{ Dias de exposição à luz } \\
\hline & 5 & 10 & 15 & 20 & 25 \\
\hline Ágata & $4,01 \mathrm{a}$ & $6,71 \mathrm{ab}$ & $7,05 \mathrm{abc}$ & $8,24 a b c$ & $8,66 \mathrm{ab}$ \\
\hline Ambra & $5,54 \mathrm{a}$ & $5,97 \mathrm{ab}$ & $6,52 b c$ & $7,34 \mathrm{abc}$ & $8,35 b$ \\
\hline Annabelle & $4,02 \mathrm{a}$ & $4,22 b$ & $4,51 \mathrm{c}$ & $5,25 \mathrm{c}$ & $6,36 b$ \\
\hline Asterix & $5,19 \mathrm{a}$ & $5,92 \mathrm{ab}$ & $8,62 \mathrm{ab}$ & $8,90 \mathrm{abc}$ & $9,32 \mathrm{ab}$ \\
\hline Atlantic & $7,79 \mathrm{a}$ & $8,35 \mathrm{a}$ & $8,43 a b$ & $8,65 \mathrm{abc}$ & $8,67 b$ \\
\hline Cupido & $4,15 \mathrm{a}$ & $5,75 \mathrm{ab}$ & $-(2)$ & - & - \\
\hline Daisy & $4,09 \mathrm{a}$ & $7,17 \mathrm{ab}$ & $7,65 \mathrm{ab}$ & $8,13 a b c$ & $9,64 \mathrm{ab}$ \\
\hline Fontane & $4,89 \mathrm{a}$ & $5,78 \mathrm{ab}$ & $6,29 b c$ & $6,29 b c$ & $6,71 b$ \\
\hline Innovator & $6,79 a$ & $7,40 \mathrm{ab}$ & $9,21 \mathrm{a}$ & $9,34 \mathrm{ab}$ & $9,61 \mathrm{ab}$ \\
\hline Markies & $4,82 \mathrm{a}$ & $5,83 \mathrm{ab}$ & $6,83 \mathrm{abc}$ & 7,37abc & $7,73 b$ \\
\hline Voyager & $6,86 \mathrm{a}$ & $8,84 \mathrm{a}$ & $9,41 \mathrm{a}$ & $11,06 \mathrm{a}$ & $12,93 \mathrm{a}$ \\
\hline CV (\%) & 33,1 & 27,5 & 18,8 & 22,2 & 23,2 \\
\hline
\end{tabular}

${ }^{(1)}$ Médias seguidas de letras iguais, nas colunas, não diferem entre si pelo teste Tukey, a 5\% de probabilidade. ${ }^{(2)}$ Não avaliada, em virtude do apodrecimento dos tubérculos. 
entre as demais cultivares. Nesse período, a avaliação de esverdeamento na cultivar Cupido foi interrompida, em virtude do apodrecimento dos tubérculos. Com 15 dias de exposição, as cultivares Innovator e Voyager apresentaram maior diferença na cor da película que as cultivares Annabelle, Ambra e Fontane, enquanto, nas demais cultivares, a intensidade de esverdeamento foi semelhante.

Aos 20 dias de exposição, apenas a cultivar Voyager apresentou maior intensidade de esverdeamento que as cultivares Annabelle e Fontane. Na última avaliação, a intensidade de esverdeamento observada na cultivar Voyager aumentou ainda mais e passou a ser superior à verificada nas cultivares Annabelle, Ambra, Atlantic, Fontane e Markies (Tabela 3). As diferenças observadas entre as cultivares testadas estão de acordo com Grunenfelder et al. (2006) e Fernandes et al. (2011), que relataram que a intensidade de esverdeamento dos tubérculos de batata, quando expostos às mesmas condições indutoras, varia com a cultivar utilizada. A partir dos 15 dias de exposição, os valores de diferença de cor ficaram entre 6,0 e 12,0, ou seja, a partir dessa época todas as cultivares apresentaram variação de cor facilmente distinguível, exceto a cultivar Voyager que foi a mais sensível ao esverdeamento desde os dez dias de exposição (Tabela 3).

No geral, o armazenamento apresentou um efeito típico de induzir o esverdeamento em todas as cultivares avaliadas. No entanto, ao longo do período de avaliação, a cultivar Voyager foi a mais suscetível, e a cultivar Annabelle foi a mais resistente ao esverdeamento pós-colheita.

\section{Conclusões}

1. As cultivares Ágata, Ambra, Annabelle, Cupido e Voyager apresentam tubérculos com características adequadas para o mercado fresco, preparação de massas e uso culinário.

2. Os tubérculos das cultivares Atlantic, Fontane e Innovator apresentam características adequadas para fritura, enquanto as cultivares Asterix e Markies são indicadas para o preparo de massas e fritura.

3. As cultivares Innovator e Markies apresentam melhor qualidade nutricional, com elevados teores da maioria dos minerais e de proteína, e as cultivares Ágata e Ambra apresentam menor qualidade nutricional e proteica.
4. A cultivar Voyager apresenta maior esverdeamento pós-colheita do que as cultivares Annabelle, Fontane, Markies, Ambra e Atlantic.

\section{Agradecimentos}

Ao Conselho Nacional de Desenvolvimento Científico e Tecnológico, pela concessão de bolsa de Produtividade em Pesquisa ao ultimo autor.

\section{Referências}

BÁRTOVÁ, V.; BÁRTA, J. Chemical composition and nutritional value of protein concentrates isolated from potato (Solanum tuberosum L.) fruit juice by precipitation with ethanol or ferric chloride. Journal of Agricultural and Food Chemistry, v.57, p.9028-9034, 2009.

BRAUN, H.; FONTES, P.C.R.; FINGER, F.L.; BUSATO, C.; CECON, P.R. Carboidratos e matéria seca de tubérculos de cultivares de batata influenciados por doses de nitrogênio. Ciência e Agrotecnologia, v.34, p.285-293, 2010.

BRUNE, S.; MELO, P.E. Método rápido de avaliação do esverdeamento em tubérculos de batata. Pesquisa Agropecuária Brasileira, v.36, p.809-814, 2001.

FELTRAN, J.C.; LEMOS, L.B.; ARTIOLI, G.M.; BANZATTO, D.A. Esverdeamento em cultivares de batata avaliado pela escala visual e índice spad. Horticultura Brasileira, v.22, p.681-685, 2004a.

FELTRAN, J.C.; LEMOS, L.B.; VIEITES, R.L. Technological quality and utilization of potato tubers. Scientia Agricola, v.61, p.598-603, 2004b.

FERNANDES, A.M.; SORATTO, R.P.; EVANGELISTA, R.M.; NARDIN, I. Qualidade físico-química e de fritura de tubérculos de cultivares de batata na safra de inverno. Horticultura Brasileira, v.28, p.299-304, 2010a.

FERNANDES, A.M.; SORATTO, R.P.; EVANGELISTA, R.M.; SILVA, B.L.; SOUZA-SCHLICK, G.D. de. Produtividade e esverdeamento pós-colheita de tubérculos de cultivares de batata produzidos na safra de inverno. Revista Ciência Agronômica, v.42, p.502-508, 2011.

FERNANDES, A.M.; SORATTO, R.P.; SILVA, B.L.; SOUZA-SCHLICK, G.D. de. Crescimento, acúmulo e distribuição de matéria seca em cultivares de batata na safra de inverno. Pesquisa Agropecuária Brasileira, v.45, p.826-835, $2010 \mathrm{~b}$.

FREITAS, S.T. de; BISOGNIN, D.A.; GÓMEZ,A.C.S.; SAUTTER, C.K.; COSTA, L.C. da; RAMPELOTTO, M.V. Qualidade para processamento de clones de batata cultivados durante a primavera e outono no Rio Grande do Sul. Ciência Rural, v.36, p.80-85, 2006.

GRUNENFELDER, L.; HILLER, L.K.; KNOWLES, N.R. Color indices for the assessment of chlorophyll development and greening of fresh market potatoes. Postharvest Biology and Technology, v.40, p.73-81, 2006. 
HORWITZ, W.; LATIMER JUNIOR, G.W. Official methods of analysis of the Association of Analytical Chemists International. $18^{\text {th }}$ ed. Gaythersburg: AOAC International, 2005.

KONICA MINOLTA. Comunicação precisa da cor: controle de qualidade da percepção à instrumentação. Seoul: Konica Minolta, 1998. 53p. Disponível em: <www.konicaminolta.com/sensingusa/ support/product_applications>. Acesso em: 15 fev. de 2011.

LACHMAN, J.; HAMOUZ, K; DVORÁK, P.; ORSÁK, M. The effect of selected factors on the content of protein and nitrates in potato tubers. Plant Soil and Environment, v.51, p.431-438, 2005 .

LISTER, C.E.; MUNRO, J. Nutrition and health qualities of potatoes - a future focus. New Zealand: New Zealand Institute for Crop and Food Research Limited, 2000. 47p. (Crop and food research confidential report, 143).

MALAVOLTA, E.; VITTI, G.C.; OLIVEIRA, S.A. de. Avaliação do estado nutricional das plantas: princípios e aplicações. Piracicaba: Associação Brasileira para Pesquisa da Potassa e do Fosfato, 1997. 319p.

MISRA, A.; KULSHRESTHA, K. Effect of storage on nutritional value of potato flour made from three potato varieties. Plant Foods for Human Nutrition, v.58, p.1-10, 2003.

MURAJA-FRAS, J.; KRSNIK-RASOL, M.; WRISCHER, M. Plastid transformation in greening potato tuber tissue. Journal of Plant Physiology, v.144, p.58-63, 1994.

NELSON, N. A photometric adaptation of the Somogyi method for the determination of glucose. Journal of Biological Chemistry, v.153, p.375-390, 1944.

OLIVEIRA, V.R. de; ANDRIOLO, J.L.; BISOGNIN, D.A.; PAULA, A.L. de; TREVISAN, A.P.; ANTES, R.B. Qualidade de processamento de tubérculos de batata produzidos sob diferentes disponibilidades de nitrogênio. Ciência Rural, v.36, p.660-663, 2006.
PEDRESCHI, F.; LEON, J.; MERY, D.; MOYANO, P.; PEDRESCHI, R.; KAACK, K.; GRANBY, K. Color development and acrylamide content of pre-dried potato chips. Journal of Food Engineering, v.79, p.786-793, 2007.

PEREIRA, A.S. Composição química, valor nutricional e industrialização. In: REIFSCHNEIDER, F.J.B. (Ed.). Produção de batata. Brasília: Linha Gráfica, 1987. p.12-28.

PEREIRA, E.M.S.; LUZ, J.M.Q.; MOURA, C.C. A batata e seus benefícios nutricionais. Uberlândia: EDUFU, 2005. 60p.

PINELLI, L.L.O.; MORETTI, C.L.; ALMEIDA, G.C.; ONUKI, A.C.A.; NASCIMENTO, A.B.G. Caracterização química e física de batatas 'Ágata' minimamente processadas, embaladas sob diferentes atmosferas modificadas ativas. Pesquisa Agropecuária Brasileira, v.40, p.1035-1041, 2005.

QUADROS, D.A. de; JUNG, M.C.; FERREIRA, S.M.R.; FREITAS, R.J.S. de. Composição química de tubérculos de batata para processamento, cultivados sob diferentes doses e fontes de potássio. Ciência e Tecnologia de Alimentos, v.29, p.316-323, 2009.

SILVA, G.O.; PEREIRA, A. da S.; SOUZA, V.Q.; CARVALHO, F.I.F.; FRITSCHE NETO, R. Correlações entre caracteres de aparência e rendimento e análise de trilha para aparência de batata. Bragantia, v.66, p.381-388, 2007.

STARK, J.C.; OLSEN, N.; KLEINKOPF, G.E.; LOVE, S.L. Tuber quality. In: STARK, J.C.; LOVE, S.L. (Ed.). Potato production systems. Aberdeen: University of Idaho, 2003. p.329-343.

ZENEBOM, O.; PASCUET, N.S. Ministério da Saúde. Agência Nacional de Vigilância Sanitária. Métodos físico-químicos para análise de alimentos. 4.ed. Brasília: Ministério da Saúde, 2005. $1018 \mathrm{p}$.

ZORZELLA, C.A.; VENDRUSCOLO, J.L.; TREPTOW, R.O.; ALMEIDA, T.L. de. Caracterização física, química e sensorial de genótipos de batata processados na forma de chips. Brazilian Journal of Food Technology, v.6, p.15-24, 2003.

$\overline{\text { Recebido em 1ํ de março de } 2011 \text { e aprovado em } 3 \text { de agosto de } 2011}$ 